\title{
The Influence of Asian Subgroup and Acculturation on Colorectal Cancer Screening Knowledge and Attitudes Among Chinese and Korean Americans
}

\author{
Brittany N. Morey ${ }^{1}\left[\right.$ Connie Valencia ${ }^{2} \cdot$ Sunmin Lee $^{3}$
}

Accepted: 25 May 2021 / Published online: 9 June 2021

(c) American Association for Cancer Education 2021

\begin{abstract}
Understanding how knowledge and attitudes about colorectal cancer (CRC) screening differs among Asian immigrants is important for informing targeted health interventions aimed at preventing and treating CRC in this diverse population. This study examines how Asian subgroup and acculturation are associated with CRC knowledge and attitudes among Chinese and Korean immigrants in the United States (U.S.). Data come from the baseline survey of a randomized controlled trial to increase CRC screening among Chinese and Korean American immigrants living in the Baltimore-Washington DC Metropolitan Area $(n=400)$. We use linear regression to examine how Asian subgroup, time in the U.S., English-speaking proficiency, and ethnic identity are associated with CRC knowledge and screening attitudes, accounting for demographic variables, socioeconomic status, and health insurance status. Results show that greater socioeconomic status was associated with higher CRC knowledge, and socioeconomic status explained more of the variance in CRC knowledge than acculturation factors. Additionally, attitudes varied by Asian subgroup, with Chinese reporting lower CRC screening salience, worry, response efficacy, and social influence compared to Koreans. Findings suggest that in-language interventions aimed at increasing CRC knowledge and capitalizing on attitudes about screening can help to bridge disparities in CRC screening by socioeconomic status and country of origin. We discuss implications for future interventions to increase CRC screening uptake among Chinese and Korean immigrants in the U.S.
\end{abstract}

Keywords Colorectal cancer $\cdot$ Cancer screening $\cdot$ Asian American $\cdot$ Acculturation $\cdot$ Knowledge $\cdot$ Attitudes

\section{Introduction}

If caught early through screening, colorectal cancer (CRC) is a highly treatable and preventable cancer [1]. The United States Preventive Services Task Force currently recommends all adults aged 50 to 75 be screened for CRC [2],

Brittany N. Morey

brittany.morey@uci.edu

1 Department of Health, Society, \& Behavior, Program in Public Health, University of California Irvine, $653 \mathrm{E}$. Peltason Dr., Anteater Instruction and Research Building (AIRB) 2022, Irvine, CA 92697-3957, USA

2 Department of Health, Society, \& Behavior, Program in Public Health, University of California Irvine, 653 E. Peltason Dr., Irvine, CA 92697-3957, USA

3 Department of Medicine, School of Medicine, University of California Irvine, 1001 Health Sciences Rd., Irvine, CA 92617, USA and the American Cancer Society recommends that people at average risk for $\mathrm{CRC}$ should start screening even younger at age 45 [3]. However, data show that Asian Americans have low CRC screening rates in the United States (U.S.). Estimates based on the 2018 National Health Interview Survey revealed that among the population 45 years and older, Asian Americans had the lowest prevalence of up-to-date CRC screening (defined as person being up-to-date with current age-dependent guidelines for stool test, sigmoidoscopy, colonoscopy, or computed tomographic colonography) at $55 \%$ compared to other racial groups including White $(68 \%)$, Black (65\%), and American Indian/Alaska Native (59\%) Americans [4]. These low screening rates contribute to the burden of CRC death among Asian Americans [1]. Malignant neoplasms are the number one leading cause of death among Asian Americans, whereas they are the second leading cause of death for the total U.S. population and for nonLatino White, Black, and American Indian/Alaska Native populations [5]. For Asian Americans, CRC is the second 
and third leading cause of cancer death for men and women, respectively, behind lung and breast cancers [6]. Deaths due to CRC make up a greater percentage of all cancer deaths among Chinese (10.4\% for men, $11.9 \%$ for women) and Korean (11.0\% for men, $11.4 \%$ for women) compared to non-Latino White (9.1\% for men, 9.6\% for women) Americans [6]. Therefore, understanding the barriers and facilitators of CRC screening among Asian Americans is essential for preventing CRC mortality disparities.

CRC screening uptake varies among Asian Americans by subgroup. Disaggregated data from the California Health Interview Survey show that in the state's population 50 years old and older, Chinese and Korean Americans had lower CRC screening rates $(50.7 \%$ and $32.7 \%$, respectively) compared to non-Latino White Americans (57.7\%), with Koreans having the lowest screening rate of any other Asian American subgroup [7]. Similar findings from the Baltimore-Washington DC Metropolitan Area showed the lowest rate of up-to-date CRC screening was among Korean Americans compared to other Asian subgroups [8]. Additionally, immigration-related factors are associated with CRC screening among Asian immigrants, such that those who have lived in the U.S. longer and who have greater English proficiency are more likely to undergo screening $[9,10]$. Therefore, interventions aimed at increasing CRC screening among Asian American immigrants should take into consideration Asian subgroup differences as well as factors related to acculturation. Here, we define acculturation as the "process by which individuals adapt to a new living environment and potentially adopt the norms, values, and practices of their new host society" [11].

In order to increase CRC screening among Asian immigrants in the U.S., researchers have proposed that interventions for increasing CRC knowledge and changing CRC screening attitudes would be effective [12]. Indeed, research shows that greater knowledge and positive attitudes about CRC and screening among diverse Asian groups in the U.S. are associated with a greater likelihood of engaging in CRC screening [8]. Yet, questions remain about what influences CRC knowledge and attitudes among Asian immigrants. Given the greater likelihood of Asian immigrants to receive CRC screening with longer time lived in the U.S., it seems possible that CRC knowledge and attitudes change with length of residence in the U.S. [9]. On the other hand, Asian immigrants with limited English proficiency have lower uptake of CRC screening in the U.S., so it is possible that knowledge and attitudes are dependent on ability to communicate in English [8, 9]. Alternatively, Asian immigrants vary in their ethnic identity: how closely they identify with Asian culture versus "western" culture, or whether they can navigate both cultures equally well [13]. Ethnic identity may influence Asian immigrants' willingness to receive CRC screening, and their attitudes about cancer and prevention
[9]. These three factors-time lived in the U.S., English language proficiency, and ethnic identity—are commonly used as proxies for acculturation.

The purpose of this study is to examine how Asian subgroup and proxies of acculturation are associated with CRC knowledge and screening attitudes among a cohort of Chinese and Korean immigrants. Our two hypotheses are as follows: (1) Asian subgroup and acculturation are associated with CRC knowledge, and (2) Asian subgroup and acculturation are associated with CRC attitudes. In testing these hypotheses, the goal of this paper is to better inform targeted health interventions to increase screening uptake among Chinese and Korean immigrants by addressing CRC knowledge and attitudes.

\section{Methods}

\section{Data Source}

This study examined baseline survey data from a randomized controlled trial to increase colorectal cancer screening among 200 Chinese and 200 Korean Americans $(n=400)$ residing in the Baltimore-Washington DC Metropolitan Area called Screening to Prevent Colorectal Cancer (STOP CRC). Study participants were between the ages of 50 and 75, and they were recruited from primary care physicians' clinics. The baseline survey data were collected from August 2018 to June 2020 and included questions on CRC knowledge, attitudes, and sociodemographic characteristics. Ninety-two percent of data collection was completed in-person, and the remaining $8 \%$ was collected by phone due to the COVID-19 outbreak in March 2020. After providing informed consent, participants completed a selfadministered questionnaire (for in-person data collection) or a researcher-led phone survey (for phone-based data collection) in their preferred language (Mandarin, Korean, or English). The survey questionnaires were translated first by a bilingual staff member and reviewed by a second bilingual staff member. This study was approved by the Institutional Review Boards of the University of Maryland and the University of California, Irvine.

\section{Dependent Variables}

The dependent variables included one measure of knowledge and six measures of attitudes about CRC screening. The CRC knowledge scale was a modified version of a 16 -item scale previously validated for use in diverse populations $[14,15]$. Some items were removed or adapted because they were only applicable to Black or African American populations. Our adapted knowledge scale included 13 true/ false statements about CRC facts and myths, including (1) 
"colorectal cancer is cancer of the colon or rectum," (2) "colorectal cancer affects only older White men," (3) "risk of colorectal cancer becomes greater as a person gets older," (4) "both men and women are at risk for colorectal cancer," (5) "colorectal cancer begins as a growth (a polyp) in the colon or rectum," (6) "rectal bleeding is a symptom to report to my doctor," (7) "change in bowel habits is a symptom to report to my doctor," (8) "there is nothing I can do to prevent colorectal cancer," (9) "there are several screening tests for colorectal cancer," (10) "colorectal cancer screening begins at age 50," (11) "colorectal cancer screening is not necessary if there are no symptoms," (12) "finding colorectal cancer early will save my life," and (13) "the treatment for colorectal cancer may not be as bad if the cancer is found early." Correctly answered statements resulted in 1 point each, while incorrect or "don't know" statements resulted in 0 points, creating a summed score ranging from 0 to 13 . All respondents answered all CRC knowledge items, so there were no missing data. The CRC knowledge scale had good internal reliability in the sample (Cronbach's alpha $=0.80$ ).

The CRC attitudes measure has been used in several studies and has shown good validity in diverse samples $[16,17]$. We used a slightly modified version, which included only 20 of the original 22 items, for parsimony. The six constructs used to assess CRC attitudes were salience/coherence, perceived susceptibility, worries/concerns, response efficacy, social influence, and self-efficacy for CRC screening. These scales were drawn from the preventive health model and precaution adoption process model $[18,19]$. The salience/coherence scale consisted of three items: (1) "colorectal cancer screening makes sense to me," (2) "I think that having colorectal cancer screening is an important thing for me to do," and (3) "I think having colorectal cancer screening can help to protect my health." The perceived susceptibility scale consisted of three items: (4) "I believe my chances of developing colorectal cancer is high," (5) "I think it is very likely that I will develop colorectal cancer or polyps," and (6) "I believe the chances that I will develop colorectal polyps are low." The worry/ concerns scale consisted of two items: (7) "I am afraid of having an abnormal colorectal cancer screening test result" and (8) "I am worried that colorectal cancer screening will show that I have colorectal cancer or polyps." The response efficacy scale consisted of two items: (9) "I believe when colorectal polyps are found and removed, colorectal cancer can be prevented" and (10) "I believe that when colorectal cancer is found early, it can be cured." The social influence scale consisted of four items: (11) "I want to do what members of my immediate family think I should do about colorectal cancer screening," (12) "members of my immediate family think I should have colorectal cancer screening," (13) "my doctor or health professional thinks I should have colorectal cancer screening," and (14)
"I want to do what my doctor or health professional thinks I should do about colorectal cancer screening." The selfefficacy scale consisted of six items: (15) "I think it takes too much time to go through colorectal cancer screening," (16) "I believe colorectal cancer screening is too embarrassing," (17) "I think that going through colorectal cancer screening is convenient," (18) "I think that colorectal cancer screening is painful," (19) "I believe that colorectal cancer screening is expensive," and (20) "I think that colorectal cancer screening is disgusting." Respondents provided answers to each item on a 5-point Likert scale ranging from "strongly disagree" to "strongly agree." Item responses were scored on a scale of 0 to 4 , depending on the direction of the statement in relation to the attitude. Items in the opposite direction of the attitude were reversecoded. Each attitude scale ranged from 0 to 4 -the mean score for the items in each subscale. Higher scores on each subscale indicate greater endorsement of the CRC attitude. All respondents answered all CRC attitude items, so there were no missing data.

\section{Independent Variables}

The main independent variables of interest were Asian subgroup and proxies for acculturation. Asian subgroup was self-reported identification as Chinese or Korean. Almost all Chinese respondents were born in China (one person was born in Indonesia), and all Korean respondents were born in South Korea. The three proxies for acculturation were years in the U.S., English-speaking proficiency, and ethnic identity. The number of years lived in the U.S. was calculated by subtracting the respondent's reported year of immigration from the year of interview. Englishspeaking proficiency was determined by the question "How well do you speak English?" and was categorized as "poorly/not at all," "so-so," or "fluently/well." Ethnic identity was determined by asking whether respondents rated themselves as "very Asian," "mostly Asian," "bicultural," "mostly westernized," or "very westernized." As few respondents identified as mostly or very westernized, this variable was collapsed into three categories: "very Asian," "mostly Asian," or "bicultural/westernized."

Demographic characteristics included age (in years), gender (female or male), and marital status (not currently married or married/cohabitating). Socioeconomic factors included education (high school graduate or less, some college or college graduate, or graduate or professional school), income (less than $\$ 20,000, \$ 20,000-\$ 59,999$, $\$ 60,000-\$ 99,999$, or $\$ 100,000$ or more), and employment (full time, part time, or not employed). Lastly, we accounted for health insurance status (private insurance, Medicare/Medicaid, or no health insurance). 


\section{Analysis}

We conducted the analyses using Stata, version 16. First, we calculated descriptive statistics for the entire sample and then stratified by Asian subgroup (Korean or Chinese). Means and standard deviations are presented for continuous variables: age, years in the U.S., CRC knowledge, and $\mathrm{CRC}$ attitudes. Frequencies and percentages are presented for categorical variables: gender, marital status, education, income, employment, health insurance, English proficiency, and ethnic identity. We used $t$ tests (for continuous variables) and chi-square tests (for categorical variables) to determine $p$ values for differences between the Korean and Chinese samples on the variables. Next, we conducted a series of multivariable linear regression models estimating CRC knowledge and the six CRC attitudes on Asian subgroup, acculturation variables, and other social determinants of health. The first model included only Asian subgroup and acculturation variables. The second model added demographic characteristics. The third model added socioeconomic variables and health insurance status. For the six CRC attitudes, the coefficients for the main independent variables did not change much across models, so we only presented the third fully-adjusted model. In regression models, significance levels were reported as follows: ${ }^{\dagger} p<0.1,{ }^{*} p<0.05$, $* * p<0.01$, and $* * * p<0.001$.

\section{Results}

We provide descriptive statistics for the total sample and separately for Korean and Chinese Americans in Table 1. Average age in the sample was 58 years old. Korean Americans were older on average (60 years old) compared to Chinese Americans (56 years old) in the sample. Education and income varied in the sample, with Chinese Americans having a higher proportion of people having attended graduate or professional school and earning $\$ 100,000$ or more, as compared to Korean Americans. Korean and Chinese Americans differed in their insurance type, with a higher proportion of Korean Americans receiving Medicare or Medicaid when compared to Chinese Americans. With regard to proxies of acculturation, Korean Americans lived in the U.S. for longer on average, but also reported speaking English less fluently and were more likely to identify as "very Asian" compared to Chinese Americans. CRC knowledge and attitudes differed between the two Asian subgroups. On average, Korean Americans scored lower on the knowledge scale and higher on the salience, susceptibility, worry, response efficacy, and social influences scales than Chinese Americans.

Results of the linear regression models for CRC knowledge are presented in Table 2. The first model includes Asian subgroup and proxies for acculturation. Chinese and Korean
Americans did not differ significantly in their CRC knowledge, accounting for acculturation variables. Longer residency in the U.S. was associated with lower CRC knowledge, with every 10 years lived in the U.S. associated with a 0.5 lower CRC knowledge score on average. Greater English-speaking proficiency was associated with higher CRC knowledge score; participants who spoke English fluently/well scored 2.83 points higher on average on CRC knowledge than those who spoke English poorly/not at all. Ethnic identity was not strongly associated with CRC knowledge. The associations between acculturation variables and CRC knowledge remained similar in model 2 after accounting for demographic characteristics of age, gender, and marital status. Older age was associated with slightly lower CRC knowledge score. In model 3, the coefficients for acculturation variables were attenuated after accounting for socioeconomic status and health insurance: the number of years in the U.S. was no longer strongly associated and English-speaking proficiency was negligibly associated with CRC knowledge. Higher educational attainment and higher income were strongly associated with higher CRC knowledge scores, whereas employment and health insurance were not.

Table 3 shows the linear regression models for the six CRC attitudes and their associations with Asian subgroup and proxies for acculturation. As the associations between Asian subgroup, proxies for acculturation, and CRC attitudes did not differ greatly between models, only the models that included all covariates are shown. The results show differences between Chinese and Korean Americans in several of the CRC attitudes. Compared to Korean Americans, Chinese Americans reported lower salience, worry, response efficacy, and social influence scores, even after accounting for demographic, socioeconomic, and health insurance factors. Chinese Americans also reported lower susceptibility scores than Korean Americans, although this difference was only marginally significant. The number of years in the U.S. was not highly associated with any of the six attitudes. More fluent English-speaking proficiency was associated with greater self-efficacy, even after accounting for socioeconomic and health insurance factors. Respondents who identified as "mostly Asian" had higher social influence scores than respondents who identified as either "very Asian" or "bicultural/westernized." In terms of other covariates, female participants reported lower self-efficacy than male participants, and unmarried participants had lower response efficacy and social influence compared to married participants.

\section{Discussion}

This study aims to inform interventions to increase screening for CRC among Asian Americans by examining how Asian subgroup and proxies for acculturation (years lived 
Table 1 Descriptive table (STOP CRC baseline data 2018-2020; $N=400$ )

\begin{tabular}{|c|c|c|c|c|}
\hline \multirow[t]{2}{*}{ Variable } & \multicolumn{3}{|c|}{ Frequency (\%) or mean (SD) } & \multirow{2}{*}{$\begin{array}{l}p \\
\text { value }\end{array}$} \\
\hline & Total sample $(n=400)$ & Korean $(n=200)$ & Chinese $(n=200)$ & \\
\hline Age, mean (SD) & $58.39(6.36)$ & $60.34(5.75)$ & $56.45(6.36)$ & 0.000 \\
\hline \multicolumn{5}{|l|}{ Gender, $n(\%)$} \\
\hline Male & $189(47.25)$ & $96(48)$ & $93(46.5)$ & \multirow[t]{2}{*}{0.764} \\
\hline Female & $211(52.75)$ & $104(52)$ & $107(53.5)$ & \\
\hline \multicolumn{5}{|l|}{ Marital status, $n(\%)$} \\
\hline Currently married/cohabitating & $341(85.25)$ & $169(84.5)$ & $172(86)$ & \multirow[t]{2}{*}{0.672} \\
\hline Not currently married & $59(14.75)$ & $31(15.5)$ & $28(14)$ & \\
\hline \multicolumn{5}{|l|}{ Education, $n(\%)$} \\
\hline High school graduate or less & $134(33.5)$ & $76(38)$ & $58(29)$ & \multirow{3}{*}{0.000} \\
\hline Some college or college graduate & $169(42.25)$ & $100(50)$ & $69(34.5)$ & \\
\hline Graduate or professional school & $97(24.25)$ & $24(12)$ & $73(36.5)$ & \\
\hline \multicolumn{5}{|l|}{ Income, $n(\%)$} \\
\hline Less than $\$ 20,000$ & $62(15.5)$ & $27(13.5)$ & $35(17.5)$ & \multirow[t]{4}{*}{0.000} \\
\hline$\$ 20,000-\$ 59,999$ & $149(37.25)$ & $93(46.5)$ & $56(28)$ & \\
\hline$\$ 60,000-\$ 99,999$ & $81(21.25)$ & $45(22.5)$ & $36(18)$ & \\
\hline$\$ 100,000$ or more & $108(27)$ & 35 (17.5) & $73(36.5)$ & \\
\hline \multicolumn{5}{|l|}{ Employment, $n(\%)$} \\
\hline Full time & $231(57.75)$ & $109(54.5)$ & $122(61)$ & \multirow[t]{3}{*}{0.048} \\
\hline Part time & $84(21)$ & $52(26)$ & $32(16)$ & \\
\hline Not employed & $85(21.25)$ & $39(19.5)$ & $46(23)$ & \\
\hline \multicolumn{5}{|l|}{ Health insurance, $n(\%)$} \\
\hline Private insurance & $242(60.5)$ & $104(52)$ & $138(69)$ & \multirow[t]{3}{*}{0.000} \\
\hline Medicare/Medicaid & $74(18.5)$ & $57(28.5)$ & $17(8.5)$ & \\
\hline None & $84(21)$ & $39(19.5)$ & $45(22.5)$ & \\
\hline Years in the U.S.: mean (SD) & $23.11(10.28)$ & $26.64(9.79)$ & $19.58(9.53)$ & 0.000 \\
\hline \multicolumn{5}{|l|}{ English proficiency, $n(\%)$} \\
\hline Poorly/not at all & $161(40.25)$ & $81(40.5)$ & $80(40)$ & \multirow[t]{3}{*}{0.000} \\
\hline So-so & $148(37)$ & $89(44.5)$ & $59(29.5)$ & \\
\hline Fluently/well & $91(22.75)$ & $30(15)$ & $61(30.5)$ & \\
\hline \multicolumn{5}{|l|}{ Ethnic identity, $n(\%)$} \\
\hline Very Asian & $242(60.5)$ & $172(86)$ & $70(35)$ & \multirow[t]{3}{*}{0.000} \\
\hline Mostly Asian & $62(15.5)$ & $2(1)$ & $60(30)$ & \\
\hline Bicultural/westernized & $96(24)$ & $26(13)$ & $70(35)$ & \\
\hline CRC knowledge (range: 0-13): mean (SD) & $8.95(3.14)$ & $8.49(3.04)$ & $9.41(3.17)$ & 0.003 \\
\hline \multicolumn{5}{|l|}{ CRC attitudes (range: 0-4): mean (SD) } \\
\hline Salience & $3.32(0.64)$ & $3.55(0.60)$ & $3.10(0.60)$ & 0.000 \\
\hline Susceptibility & $1.65(0.65)$ & $1.72(0.68)$ & $1.58(0.61)$ & 0.030 \\
\hline Worry & $2.05(1.00)$ & $2.26(1.06)$ & $1.85(0.89)$ & 0.000 \\
\hline Response efficacy & $3.15(0.67)$ & $3.33(0.73)$ & $2.96(0.56)$ & 0.000 \\
\hline Social influence & $2.88(0.67)$ & $2.99(0.75)$ & $2.77(0.56)$ & 0.001 \\
\hline Self-efficacy & $2.17(0.59)$ & $2.13(0.65)$ & $2.22(0.52)$ & 0.126 \\
\hline
\end{tabular}

$t$ tests and chi-square tests were used to determine the $p$ values of differences between Korean and Chinese subgroups on variables

in the U.S., English proficiency, and ethnic identity) were associated with CRC knowledge and attitudes. We found that socioeconomic status was more strongly associated with CRC knowledge and Asian subgroup was strongly associated with several CRC attitudes. Previous studies have found Asian immigrants who have lived longer in the U.S. and have greater English proficiency have higher CRC screening uptake [9]. Furthermore, Asian American subgroups 
Table 2 Linear regression of colorectal cancer knowledge on Asian subgroup, acculturation variables, and covariates (STOP CRC baseline data 2018-2020; $N=400$ )

\begin{tabular}{|c|c|c|c|}
\hline \multirow[t]{2}{*}{ Variables } & \multicolumn{3}{|l|}{ Coefficient (SE) } \\
\hline & Model 1 & Model 2 & Model 3 \\
\hline \multicolumn{4}{|l|}{ Asian subgroup } \\
\hline Korean & ref & ref & ref \\
\hline Chinese & $0.37(0.39)$ & $0.21(0.39)$ & $0.27(0.40)$ \\
\hline Years in the U.S. (10 years) & $-0.50 * *(0.18)$ & $-0.37 *(0.18)$ & $-0.24(0.19)$ \\
\hline \multicolumn{4}{|l|}{ English-speaking proficiency } \\
\hline Poorly/not at all & ref & ref & ref \\
\hline So-so & $1.59 * * *(0.37)$ & $1.37 * * *(0.38)$ & $0.48(0.43)$ \\
\hline Fluently/well & $2.83 * * *(0.45)$ & $2.51 * * *(0.48)$ & $1.11^{\dagger}(0.62)$ \\
\hline \multicolumn{4}{|l|}{ Ethnic identity } \\
\hline Very Asian & ref & ref & ref \\
\hline Mostly Asian & $0.23(0.49)$ & $0.29(0.49)$ & $0.064(0.49)$ \\
\hline Bicultural/westernized & $-0.30(0.42)$ & $-0.27(0.42)$ & $-0.53(0.42)$ \\
\hline Age & & $-0.060 *(0.026)$ & $-0.049^{\dagger}(0.029)$ \\
\hline \multicolumn{4}{|l|}{ Gender } \\
\hline Male & & ref & ref \\
\hline Female & & $0.45(0.30)$ & $0.53^{\dagger}(0.31)$ \\
\hline \multicolumn{4}{|l|}{ Marital status } \\
\hline Married/cohabitating & & ref & ref \\
\hline Not married & & $-0.19(0.43)$ & $-0.16(0.43)$ \\
\hline \multicolumn{4}{|l|}{ Education } \\
\hline Less than high school & & & ref \\
\hline Some college or college graduate & & & $0.90 *(0.39)$ \\
\hline Graduate or professional school & & & $1.19 *(0.57)$ \\
\hline \multicolumn{4}{|l|}{ Income } \\
\hline Less than $\$ 20,000$ & & & ref \\
\hline$\$ 20,000-\$ 59,999$ & & & $0.72(0.49)$ \\
\hline$\$ 60,000-\$ 99,999$ & & & $1.55 * *(0.56)$ \\
\hline$\$ 100,000$ or more & & & $1.64 * *(0.62)$ \\
\hline \multicolumn{4}{|l|}{ Employment } \\
\hline Full time & & & ref \\
\hline Part time & & & $-0.32(0.40)$ \\
\hline Not employed & & & $-0.13(0.44)$ \\
\hline \multicolumn{4}{|l|}{ Health insurance } \\
\hline Private insurance & & & ref \\
\hline Medicare/Medicaid & & & $0.074(0.48)$ \\
\hline None & & & $0.26(0.40)$ \\
\hline Constant & $8.73 * * *(0.47)$ & $11.9 * * *(1.62)$ & $9.98 * * *(1.84)$ \\
\hline$R^{2}$ & 0.117 & 0.135 & 0.191 \\
\hline
\end{tabular}

$S E$ standard error

${ }^{\dagger} p<0.1 ; * p<0.05$; ** $p<0.01 ; * * * p<0.001$ differ in their CRC screening rates [7,8]. These studies led us to hypothesize that Asian subgroup and proxies for acculturation would predict CRC screening knowledge and attitudes, which might help explain why screening is more prevalent among some Asian American groups more than others. However, our study finds that acculturation may not be the most relevant factor influencing CRC knowledge and attitudes.
Contrary to our first hypothesis, CRC knowledge did not differ by Asian subgroup or acculturation variables, accounting for all else. Chinese and Korean Americans were similar in their CRC knowledge in regression analyses. Furthermore, associations between time spent in the U.S. and English-speaking proficiency were greatly attenuated after accounting for socioeconomic status. Greater English-speaking proficiency remained only modestly 


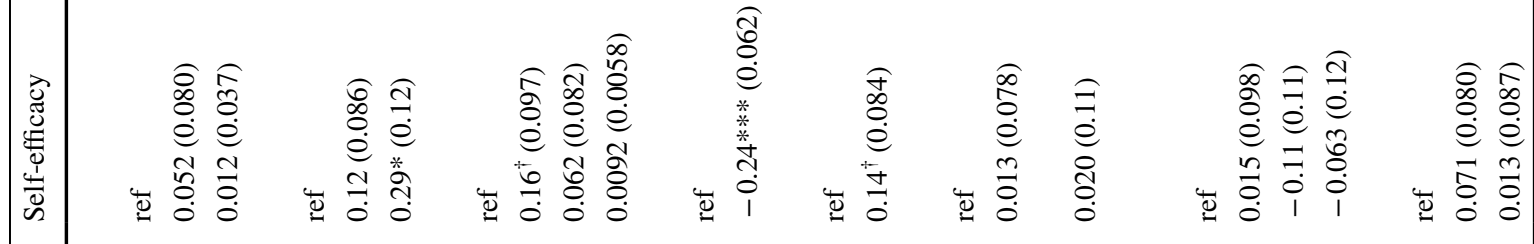

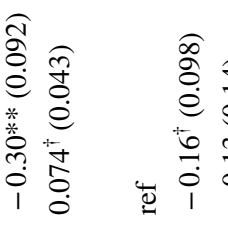

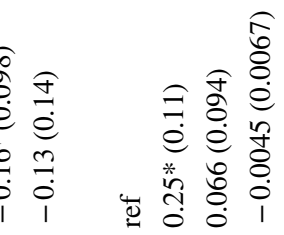

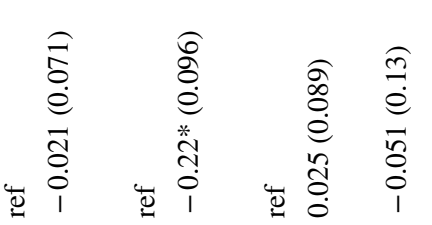

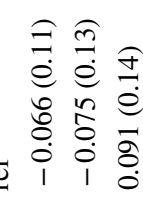

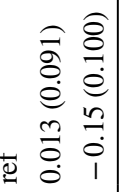

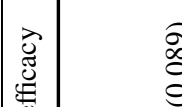

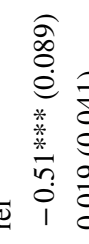

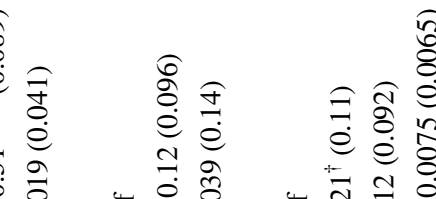

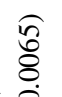

\&

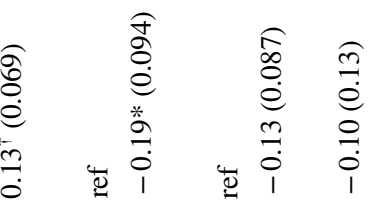

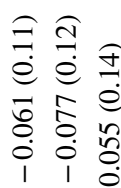

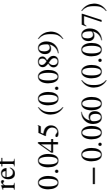

$\checkmark$ i

$=0 \% 1$

बิ?

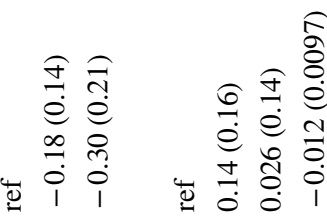

容

送

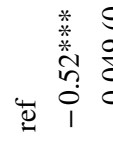

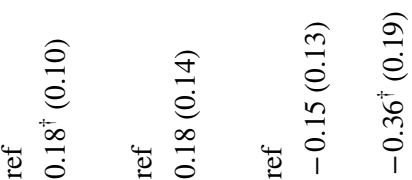

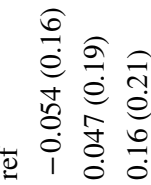

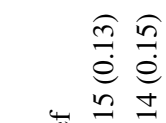

을

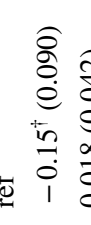

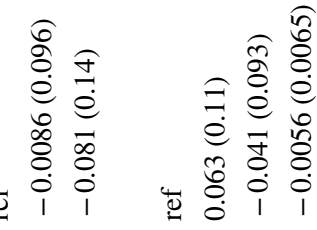

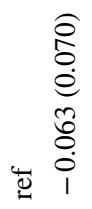

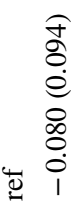

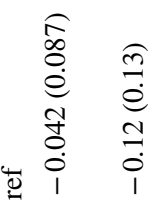

‡)

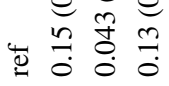

巴)

犬ํㅇㅇ

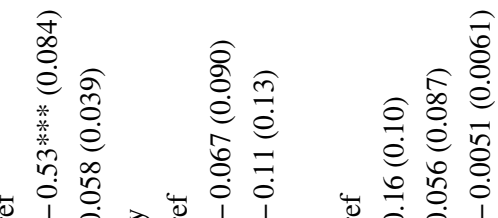

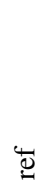

受

赛

罯

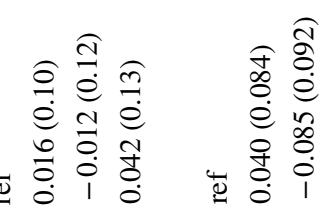

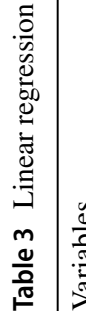

. 离 Ð

은

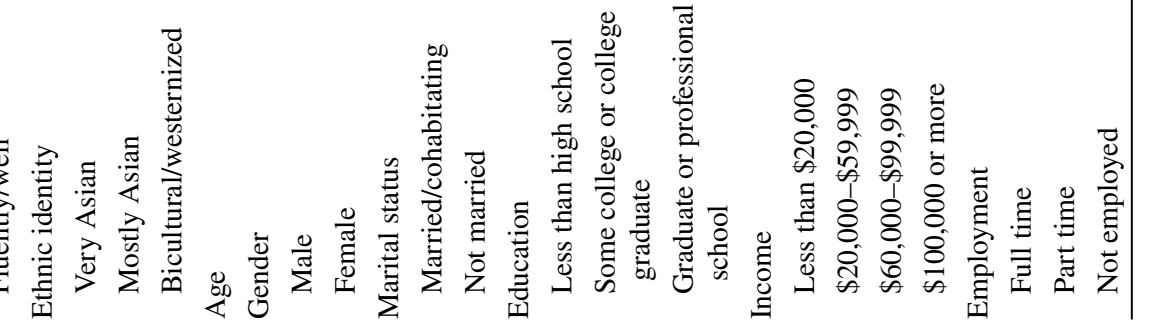




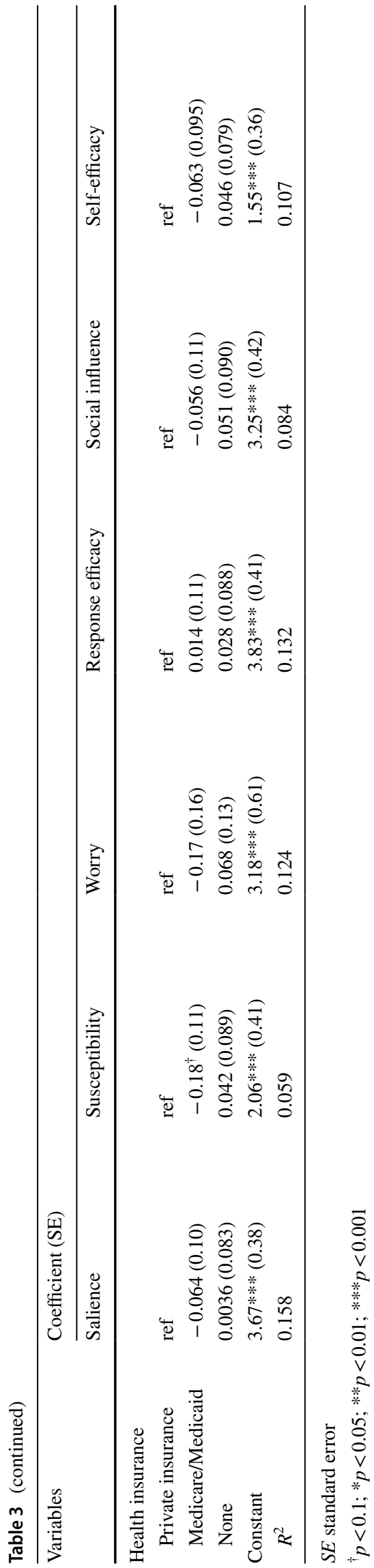

associated with greater CRC knowledge after including education and income. On the other hand, higher educational attainment and higher income levels were strongly associated with greater CRC knowledge. These findings indicate that the strongest predictors of CRC knowledge among Chinese and Korean Americans were education and income. This highlights the importance of increasing CRC knowledge through education efforts that are accessible and in-language, especially for Asian American immigrants with low income and low education [20,21].

Our study found some support for our second hypothesis. First, CRC attitudes varied by Asian subgroup. Korean participants reported higher scores than Chinese participants for four out of the six attitudes: salience, worry, response-efficacy, and social influence. Although studies have previously shown that Korean Americans have some of the lowest rates of CRC screening uptake compared to other Asian American subgroups [7], attitudes about salience/coherence (how important or prominent CRC screening is in the patient's psyche), worry about CRC, response efficacy (belief that undergoing CRC screening is effective for preventing disease and death), and social influence (how strongly a patient is influenced by the beliefs of those in their social network) are high among Korean Americans in our sample. These attitudes should be considered when tailoring health interventions to increase CRC screening among Korean Americans. It is possible that excessive salience and worry could create fear that prevents some Korean Americans from undergoing CRC screening. Therefore, interventions targeting Korean American populations may address excessive worry by increasing understanding of the preventable nature of CRC and by explaining clearly what CRC screening entails. Social influence is high among Korean Americans, so interventions can mobilize doctors and family members to encourage their Asian American patients and relatives 50 years old and older to be screened. Lastly, the fact that response efficacy is high means that Korean Americans may be activated to undergo screening. Increasing access to preventative care will likely improve Korean Americans' uptake of screening. Interventions should consider incorporating cues to action that would remind Asian American populations to undergo screening.

In this study, social influence differed by ethnic identity. Interestingly, Chinese and Korean American patients identifying as "mostly Asian" compared to either "very Asian" or "bicultural/westernized" were more likely to be influenced by their immediate family members or healthcare providers to get screened for CRC. This is an indication that Asian American immigrants who have mostly Asian social networks are most likely to be influenced by their connections to receive CRC screening [9, 22, 23]. Future work should explore this further.

CRC self-efficacy is an important indicator of patients' judgment about how well they could go through with CRC 
screening, considering the perceived barriers [24]. Our findings revealed that English-speaking proficiency was associated with greater self-efficacy, even after accounting for demographic characteristics, socioeconomic status, and healthcare access. Other research studies found that CRC self-efficacy is associated with language, such that Chinese and Korean American patients with greater English-speaking proficiency have an easier time understanding medical terminology and navigating healthcare provider interactions [25]. Therefore, interventions should focus on increasing CRC self-efficacy especially among Asian immigrants with limited English proficiency, by providing skills and confidence to communicate with their healthcare providers about CRC screening specifically.

This study has some limitations that should be noted. The data are cross-sectional, so direction and causality could not be determined. However, as Asian subgroup and acculturation likely affect CRC knowledge and attitudes, rather than knowledge and attitudes affecting subgroup or acculturation, we can assume that the direction of our hypotheses is not a major issue. Nevertheless, there may be unaccounted for factors that influenced associations with knowledge and attitudes that were not captured in this survey, such as specific contexts that led to immigration for patients, which likely affected survey respondents' family and living situations in the U.S. [26, 27]. This study also does not include data on CRC screening behaviors, so it is unclear whether different levels of CRC knowledge and attitudes are translating to CRC screening. Furthermore, survey respondents were sampled through primary care providers in Maryland and Virginia. Therefore, these findings may not be generalizable to Chinese and Korean immigrants who do not have primary care providers or who reside outside of Maryland and Virginia. Despite these limitations, this is one of the few studies that examines CRC knowledge and attitudes that affect screening in a group of Asian American immigrants. The inclusion of Chinese and Korean Americans allows this study to examine differences by Asian subgroup, which is an indicator of the different overall histories of immigration as well as different cultural backgrounds. Lastly, this is one of the few studies that used multiple proxies for acculturationyears in the U.S., English language proficiency, and ethnic identity - to examine previously untested hypotheses about how acculturation affects CRC knowledge and attitudes.

Notably, our study found that acculturation through living in the U.S. longer does not have a strong effect on CRC knowledge and attitudes, after accounting for socioeconomic status. Interventions aimed at increasing CRC screening among Chinese and Korean immigrants may focus less on the assumption CRC screening uptake depends on adopting a Western or American notion of cancer prevention. Instead, interventions to increase CRC screening among Asian immigrants should be made available in Asian languages and be targeted for people with lower educational attainment and income. Efforts to decrease excessive worry, to mobilize social networks, to increase preventive healthcare access, and to incorporate cues to action may be especially effective in addressing CRC screening disparities among Asian immigrants in the U.S.

Acknowledgements The content is solely the responsibility of the authors and does not necessarily represent the official views of the National Institutes of Health. The authors thank Jung In Park, Ph.D., Grace Eunyoung Lee, and Soomin Ryu for their input on the analysis.

Author Contribution All authors contributed to the conceptualization and editing. Methodology, analyses, and writing of the initial draft, and manuscript revision were completed by Brittany N. Morey. Literature review, writing, and editing were provided by Connie Valencia. Supervision, data collection, provision of critical input to analysis, manuscript revision, and funding acquisition were performed by Sun$\min$ Lee.

Funding This research was supported by the National Institute on Minority Health and Health Disparities (NIMHD) of the National Institutes of Health under award number R01MD012778.

Data Availability Individuals who are interested in accessing data from this manuscript should contact the corresponding author, and de-identified data may be shared in compliance with $\mathrm{NIH}$ regulations.

Code Availability Statistical codes were completed in Stata (version 16) and are available upon request.

\section{Declarations}

Ethics Approval and Consent to Participate This study received ethics approval from the Institutional Review Boards of the University of Maryland and University of California, Irvine. All respondents completed informed consent prior to participating in the study.

Consent for Publication All of the authors consented to publishing this manuscript.

Competing Interests Except the funding source, the authors have no additional conflicts of interest or competing interests to declare. The ideas expressed in this manuscript are those of the authors and are not necessarily those of the institutions or funders.

\section{References}

1. Smith RA, Andrews KS, Brooks D, Fedewa SA, ManassaramBaptiste D, Saslow D, Brawley OW, Wender RC (2017) Cancer screening in the United States, 2017: a review of current American Cancer Society guidelines and current issues in cancer screening. CA Cancer J Clin 67(2):100-121. https://doi.org/ $10.3322 /$ caac. 21392

2. US Preventive Services Task Force (2016) Screening for colorectal cancer: US Preventive Services Task Force Recommendation Statement. JAMA 315(23):2564-2575. https://doi.org/10. 1001/jama.2016.5989

3. American Cancer Society (2020) Colorectal cancer early detection, diagnosis, and staging. American Cancer Society, Atlanta, GA 
4. American Cancer Society (2020) Colorectal cancer facts and figures 2020-2022. American Cancer Society, Atlanta

5. Heron, Melonie. 2019. Deaths: leading causes for 2017. In National Vital Statistics Reports. Hyattsville, MD: National Center for Health Statistics.

6. Thompson CA, Gomez SL, Hastings KG, Kapphahn K, Yu P, Shariff-Marco S, Bhatt AS et al (2016) The burden of cancer in Asian Americans: a report of national mortality trends by Asian ethnicity. Cancer Epidemiol Biomarkers Prev 25(10):13711382. https://doi.org/10.1158/1055-9965.Epi-16-0167

7. Lee HY, Lundquist M, Ju E, Luo X, Townsend A (2011) Colorectal cancer screening disparities in Asian Americans and Pacific Islanders: which groups are most vulnerable? Ethn Health 16(6):501-518. https://doi.org/10.1080/13557858.2011. 575219

8. Juon HS, Guo J, Kim J, Lee S (2018) Predictors of colorectal cancer knowledge and screening among Asian Americans aged 50-75 years old. J Racial Ethn Health Disparities 5(3):545-552. https://doi.org/10.1007/s40615-017-0398-1

9. Lee S, Chen L, Jung MY, Baezconde-Garbanati L, Juon HS (2014) Acculturation and cancer screening among Asian Americans: role of health insurance and having a regular physician. J Community Health 39(2):201-212. https://doi.org/10.1007/ s10900-013-9763-0

10. Ma GX, Wang MQ, Toubbeh J, Tan Y, Shive S, Wu D (2012) Factors associated with colorectal cancer screening among Cambodians, Vietnamese, Koreans and Chinese living in the United States. N Am J Med Sci (Boston) 5(1):1-8. https://doi.org/10. 7156/v5i1p001

11. Abraído-Lanza AF, Echeverría SE, Flórez KR (2016) Latino immigrants, acculturation, and health: promising new directions in research. Annu Rev Public Health 37:219-236. https://doi.org/ 10.1146/annurev-publhealth-032315-021545

12. Lu XL, Holt Ch JC, Chen D, Le J, Chen GY, Kim J, Li, Lee S (2016) Is colorectal cancer a Western disease? Role of knowledge and influence of misconception on colorectal cancer screening among Chinese and Korean Americans: a mixed methods study. Asian Pac J Cancer Prev: APJCP 17(11):4885-4892. https://doi. org/10.22034/APJCP.2016.17.11.4885

13. Iwamoto DK, Liu WM (2010) The impact of racial identity, ethnic identity, Asian values and race-related stress on Asian Americans and Asian international college students' psychological well-being. J Couns Psychol 57(1):79-91. https://doi.org/10.1037/ a0017393

14. Christou A, Thompson SC (2012) Colorectal cancer screening knowledge, attitudes and behavioural intention among Indigenous Western Australians. BMC Public Health 12:528. https://doi.org/ 10.1186/1471-2458-12-528

15. Green, P. M., and B. A. Kelly. 2004. Colorectal cancer knowledge, perceptions, and behaviors in African Americans. Cancer Nurs 27 (3):206-215; quiz 216-207. https://doi.org/10.1097/00002820200405000-00004.

16. Tiro JA, Vernon SW, Hyslop T, Myers RE (2005) Factorial validity and invariance of a survey measuring psychosocial correlates of colorectal cancer screening among African Americans and
Caucasians. Cancer Epidemiol Biomarkers Prev 14(12):28552861. https://doi.org/10.1158/1055-9965.Epi-05-0217

17. Flight IH, Wilson CJ, McGillivray J, Myers RE (2010) Crosscultural validation of the preventive health model for colorectal cancer screening: an Australian study. Health Educ Behav 37(5):724-736

18. Rosenstock IM (1974) The health belief model and preventive health behavior. Health Educ Monogr 2(4):354-386. https://doi. org/10.1177/109019817400200405

19. Weinstein, Neil D., Peter M. Sandman, and Susan J. Blalock. 2020. The precaution adoption process model. The Wiley Encyclopedia of Health Psychology: 495-506. https://doi.org/10.1002/ 9781119057840.ch100

20. Kim S, Yeon A, Cho E, Shahid M, Kim J (2019) Effectiveness of a tailored colorectal cancer educational seminar in enhancing the awareness, knowledge, and behavior of Korean Americans living in the Los Angeles Koreatown area. Divers Equal Health Care 16(1):1-8. https://doi.org/10.21767/2049-5471.1000185

21. Nguyen TT, Tsoh JY, Woo K, Stewart SL, Le GM, Burke A, Gildengorin $\mathrm{G}$ et al (2017) Colorectal cancer screening and Chinese Americans: efficacy of lay health worker outreach and print materials. Am J Prev Med 52(3):e67-e76. https://doi.org/10.1016/j. amepre.2016.10.003

22. Dong X, Liu A (2017) Variations between sources of social support and cancer screen behaviors in U.S. Chinese older adults. J Gerontol A Biol Sci Med Sci 72(suppl_1):S26-s31. https://doi. org/10.1093/gerona/glx050

23. Kim W, Kreps GL, Shin CN (2015) The role of social support and social networks in health information-seeking behavior among Korean Americans: a qualitative study. Int J Equity Health 14(1):40. https://doi.org/10.1186/s12939-015-0169-8

24. Lee SY, Lee EE (2018) Access to health care, beliefs, and behaviors about colorectal cancer screening among Korean Americans. Asian Pac J Cancer Prev: APJCP 19(7):2021-2027. https://doi. org/10.22034/APJCP.2018.19.7.2021

25. Jung MY, Holt CL, Ng D, Sim HJ, Xiaoxiao Lu, Le D, Juon H-S, Li J, Lee S (2018) The Chinese and Korean American immigrant experience: a mixed-methods examination of facilitators and barriers of colorectal cancer screening. Ethn Health 23(8):847-866

26. Gee GC, de Castro AB, Crespi C, Wang M, Hing A, Bacong A, Llave K (2019) Pre-acculturation as a risk factor for obesity: findings from the Health of Philippine Emigrants Study (HoPES). SSM - Population Health 9:100482. https://doi.org/10.1016/j. ssmph.2019.100482

27. Morey BN, Bacong AM, Hing AK, de Castro AB, Gee GC (2020) Heterogeneity in migrant health selection: the role of immigrant Visas. J Health Soc Behav 61(3):359-376. https://doi.org/10. $1177 / 0022146520942896$

Publisher's Note Springer Nature remains neutral with regard to jurisdictional claims in published maps and institutional affiliations. 